\section{BMJ Open Respiratory Research}

\title{
'It's difficult, it's life changing what happens to you' patient perspective on life with chronic hypersensitivity pneumonitis: a qualitative study
}

\author{
Kerri I Aronson, ${ }^{1}$ Bradley J Hayward, ${ }^{1}$ Laura Robbins, ${ }^{2}$ Robert J Kaner, ${ }^{1,3}$ \\ Fernando J Martinez, ${ }^{1}$ Monika M Safford ${ }^{1}$
}

To cite: Aronson Kl, Hayward BJ, Robbins L, et al. 'It's difficult, it's life changing what happens to you' patient perspective on life with chronic hypersensitivity pneumonitis: a qualitative study. BMJ Open Resp Res 2019;6:e000522. doi:10.1136/ bmjresp-2019-000522

- Additional material is published online only. To view please visit the journal online (http://dx.doi.org/10.1136/ bmjresp-2019-000522).

Received 29 October 2019 Revised 10 December 2019 Accepted 12 December 2019

Check for updates

(c) Author(s) (or their employer(s)) 2019. Re-use permitted under CC BY-NC. No commercial re-use. See rights and permissions. Published by BMJ.

${ }^{1}$ Medicine, Weill Cornell Medical College, New York, New York, USA

${ }^{2}$ Education Institute and Global Affairs, Hospital for Special Surgery, New York, New York, USA

${ }^{3}$ Institute of Genetic Medicine, Weill Cornell Medical College, New York, New York, USA

Correspondence to Dr Kerri I Aronson; kia9010@med.cornell.edu

\section{ABSTRACT}

Rationale Chronic hypersensitivity pneumonitis (CHP) is a distinct form of interstitial lung disease caused by an inhaled environmental antigen. Some patients with CHP develop progressive pulmonary fibrosis and varying degrees of symptom severity, with heterogeneous impact on functioning and overall well-being. There are no universally accepted diagnostic criteria, few FDAapproved (Food and Drug Administration) therapies and no standardised approach to identifying an antigen. The impact that living with CHP has on patients' quality of life is understudied, preventing the identification of patientcentred research questions and endpoints for future CHP clinical trials.

Objectives We explored patients' experiences, perceptions and expectations of living with CHP. Methods We conducted semistructured interviews with patients with CHP. Patients were recruited using a purposive heterogeneous sampling strategy. Interviews were audio recorded and transcribed verbatim. Data were analysed using the grounded theory method.

Results Eighteen patients were interviewed. Six major themes emerged from the interviews: (1) suffering due to lack of knowledge and uncertainty, (2) hypervigilance, (3) psychosocial, (4) physical impacts, (5) interpersonal and (6) self-perception and identity. The need to identify and avoid an antigen played a prominent role across the themes and subthemes.

Conclusions We identified several key influences on quality of life in patients with CHP that have not been adequately explored. The prevalence of these influences should be quantified, and they should be included in quality of life assessment and should guide the development of targeted interventions to improve quality of life in this patient population.

\section{INTRODUCTION}

Hypersensitivity pneumonitis (HP) is the result of an immune-mediated response in the lung after recurrent exposure to an inhaled environmental antigen. This insult results in inflammation of the lung parenchyma, and in many patients who develop chronic disease, there is a degree of permanent pulmonary
Key messages

What is the key question?

- What are the determinants of quality of life in chronic hypersensitivity pneumonitis (CHP) from the patients' perspective?

What is the bottom line?

- Several unique factors influence CHP patients' quality of life including lack of knowledge, uncertainty, impact on self-perception and identity, and the complex psychosocial problems associated with antigen identification and avoidance.

\section{Why read on?}

- Through this study, we have created a patientcentred thematic framework for quality of life that highlights patient-centred concerns specific to living with CHP, which have the potential to be the focus of future research studies as well as clinical care.

fibrosis. It is estimated that $20 \%$ of patients in the USA with interstitial lung disease (ILD) have chronic HP (CHP). ${ }^{1}$ Analysis of claimsbased data in the USA has reported annual prevalence of HP of $1.67-2.71$ cases per 100000 persons with $50 \%-63 \%$ of these classified as CHP. ${ }^{2}$ In contrast to other idiopathic interstitial pneumonia, the inciting environmental antigen adds a level of complexity in clinical diagnosis and management. Unfortunately, there are limited data on the benefits of available medical treatments. ${ }^{34}$ Although studies have shown that successful antigen avoidance is positively associated with survival, identification of a causal antigen is only possible in at most half of patients. ${ }^{56}$ These factors, coupled with the lack of international diagnostic criteria, pose a substantial challenge to clinicians. ${ }^{7}$ Moreover, one can reasonably predict that these challenges have a profound effect on patients. The available literature suggests that patients with CHP have 
poor quality of life, with worse reported generic healthrelated quality of life (HRQOL) scores and symptom severity than patients with idiopathic pulmonary fibrosis (IPF). ${ }^{8}$ These findings suggest that there may be determinants of quality life that are distinct to patients with CHP as compared with other ILDs.

There may be several reasons why patients with CHP have low HRQOL scores, such as the need to identify an inciting antigen, and the change to one's home, employment or leisure time pursuits in order to avoid that antigen. ${ }^{9}$ However, there is little reported about patients' experiences living with the disease, hampering the ability of clinicians to intervene to improve their quality of life. The objectives of this study were to describe patients' experiences, perceptions and expectations of living with CHP, and to illustrate the impact that the disease has on their quality of life.

\section{METHODS}

\section{Patient and public involvement}

The topic guide questions were generated in part by informal discussions with patients prior to the study initiation. In addition, during the study, the topic guide was adjusted based on emerging themes generated from patient responses.

\section{Participant recruitment}

This study was conducted with patients attending an urban quaternary referral centre specialty clinic serving patients with ILD. Purposive sampling was used to recruit a heterogeneous sample of patients with a wide age and disease severity range. To be included, patients had to be over the age of 18, have a diagnosis of CHP based on expert consensus and have a clinic visit within the last 2 years. Exclusions were unwillingness to undergo an audio-recorded interview, or inability to speak English.

\section{Data collection}

One-on-one semistructured interviews were conducted either in person or by telephone according to the participant's preference by one of two coauthors (KIA and $\mathrm{BJH})$. The questions for the topic guide were developed using several sources. Given there is no existing framework for living with CHP, we reviewed quality of life frameworks published in IPF. ${ }^{11}$ We also included input from ILD clinicians and conducted informal discussions with patients with CHP. The question guide is available in the online supplementary index. The interviews were audio recorded and transcribed verbatim.

\section{Data analysis}

Transcript data were coded with qualitative software (NVivo) and analysed using grounded theory. ${ }^{12}$ As interviews were completed, data were analysed in an iterative process using a constant comparative approach. ${ }^{13}$ Based on these interpretations, the topic guide was adjusted to include additional questions that further examined emerging concepts and categories. Two investigators (KIA and $\mathrm{BJH}$ ) independently coded the transcripts from the first five interviews and then compared and contrasted codes. As further transcripts were analysed, revisions to the codebook were made using selective coding and codes were then consolidated into categories. Two additional investigators (LR and MMS) assisted in reviewing and forming consensus between the categories and emerging themes. The sample size was determined based on reaching saturation, or the point where no new concepts or themes emerged from the interviews. ${ }^{14} 15$ Saturation was reached after the 12th interview, however, we conducted six more interviews in order to maximise the validity of the findings. After data analysis, respondent validation interviews were performed with four patients who had participated in the initial interviews. ${ }^{16}$

\section{RESULTS}

A total of 23 patients were approached to participate, 20 signed consent and 18 completed interviews. Two participants withdrew from the study prior to conducting an interview (see online supplementary index). There was representation from urban communities, as well as rural communities located many miles from the centre. Known exposures included home or workplace mould, farmer's lung, birds and medication. Participant characteristics are summarised in table 1 .

Six major themes emerged from the analysis that were incorporated into a theoretical framework integrating the major themes and subthemes to guide future research (figure 1). Key themes are described below and illustrated with anonymised quotes.

\section{Theme 1: there is a great deal of suffering due to lack of knowledge and uncertainty about CHP}

A lack of knowledge was pervasive. Patients described the frustration and fear that accompanies this lack of knowledge.

"I did not know which illness I had for a number of months. I knew I had a lung disease, but I didn't know which one, and it was frightening to not know. It was frightening because I had to keep waiting."

Knowledge gaps were related to defining CHP, treatment options and prognosis. Participants compared having CHP to other diseases in which there are clearer definitions, treatment options, and prognostic information.

\footnotetext{
"They say it's a disease but I heard it was just a word for, what do you call it, a lung scarring. So I don't know if that's the name of the disease, lung scarring or know exactly what the disease is."

"But this is systemic, and I can't have surgery to fix it. So I don't know how to fix it. I want it fixed."
} 


\begin{tabular}{|c|c|}
\hline Variable & Distribution \\
\hline Median age (range), y & $66.5(50-83)$ \\
\hline \multicolumn{2}{|l|}{ Gender } \\
\hline Female & 9 \\
\hline \multicolumn{2}{|l|}{ Ethnicity } \\
\hline White & 13 \\
\hline Hispanic/Latino & 2 \\
\hline Asian & 2 \\
\hline Black & 1 \\
\hline \multicolumn{2}{|l|}{ Smoking history } \\
\hline Never & 8 \\
\hline Former & 10 \\
\hline Current & 0 \\
\hline \multicolumn{2}{|l|}{ Supplemental oxygen use } \\
\hline Yes & 9 \\
\hline \multicolumn{2}{|l|}{ Presence of pulmonary fibrosis on imaging } \\
\hline Yes & 15 \\
\hline Median FVC \% predicted $\left(\right.$ range) ${ }^{\star}$ & $59(38-91)$ \\
\hline Median DLCO \% predicted (range)† & $50(32-79)$ \\
\hline \multicolumn{2}{|l|}{ Antigen identified } \\
\hline Yes & 9 \\
\hline $\begin{array}{l}\text { Median distance from ILD clinic (range), } \\
\text { miles* }^{*}\end{array}$ & $27.5(1-100)$ \\
\hline
\end{tabular}

Mean travel time to ILD clinic (SD), minutes* 82 (38.4) Identifies as having a caregiver

Yes 7

\begin{tabular}{ll}
\hline Comorbidities & \\
\hline OSA & 5 \\
\hline Pulmonary hypertension & 2 \\
\hline Asthma & 2 \\
\hline CAD & 3 \\
\hline Hypothyroid & 4 \\
\hline Depression/anxiety $\neq$ & 2 \\
\hline
\end{tabular}

${ }^{*}$ Data from 16 participants.

†Data from 17 participants.

†Formal physician diagnosis.

CAD, coronary artery disease; DLCO, Diffusing capacity of the lungs for carbon monoxide ; FVC, forced vital capacity; ILD,

interstitial lung disease; OSA, obstructive sleep apnoea; $Y$, years.

There was difficulty understanding CHP in the context of the differential diagnosis of fibrotic ILD. Some patients described a sense of relief with learning they do not have IPF, but a discomfort with not understanding the cause or trajectory of their CHP. Patients often attempted to self-educate via internet searches, desperate for information. Many patients described their future as an unknown due to uncertainty about treatment options and effects.

"I don't know if it's going to be-if that's curable, or I don't know if it's stable and you can live for the rest of your life with it like that. Or it's going to come a time when it's going to get worse? I'd like to know that.

There was a level of uncertainty related to the inciting antigen and patients described significant frustration at not knowing exactly what the culprit is.

"I think it's very frustrating to have this disease, because I don't know what causes it. I don't know what irritants cause it."

"It's really hard, because we went through a lot of ideas, a lot of suggestions. I didn't do it, I did that. Very hard.

Theme 2: development of hypervigilance influences day-today life and is related to potential antigenic stimulus, the environment and monitoring disease status

Patients described taking extra care to avoid both confirmed antigen and perceived antigenic stimulus, sometimes at the cost of otherwise planned activities. If the antigen is unknown, they cast a wider net of avoidance. The concern for contracting a contagious illness in addition to CHP was expressed by several participants, and many reported exerting substantial efforts to mitigate this risk. In some, this level of vigilance limited the ability to travel and interact socially with friends and loved ones.

"And my grandchildren are seven, five, and two. So I always kind of - if I'm going to see them, worry about them being sick because if I get sick because my immune system is compromised, I get sicker, and I think that's when I get more scar tissue.

Whether or not an antigen is known, patients described a continuous brainstorming of what they should avoid, and what potential exposures may still exist. There is an increased level of awareness and caution related to the indoor and outdoor environment mostly due to possible antigenic stimulus, but also air quality and weather.

"Going through tunnels, I'll turn off the fresh air coming into the car. Any possible triggers we avoid. Anything that's going to be mildew, musty, damp, I just don't go to those kind of places.

Some patients reported paying constant attention to their pulse oximeter, whether or not it accurately reflects symptoms of breathlessness. This generated questions about how best be proactive about self-monitoring disease status.

\section{Theme 3: living with CHP generates complex psychosocial} consequences

The psychosocial impact of living with CHP permeated throughout all of the key themes. There were feelings of pain, anxiety and depression sparked by lack of knowledge, thought of antigenic stimulants and physical constraints. Many participants relayed feelings of grief at the loss of their previous way of life. 


\begin{tabular}{|c|c|c|}
\hline Key Themes & Categories & Representative Quotes \\
\hline \multirow{4}{*}{$\begin{array}{l}\text { Suffering due to } \\
\text { lack of knowledge } \\
\text { and uncertainty }\end{array}$} & $\begin{array}{l}\text { Diagnostic uncertainty and lack } \\
\text { of information about CHP }\end{array}$ & 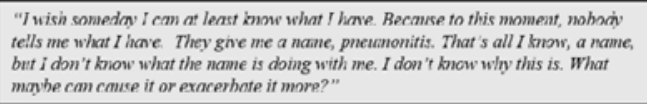 \\
\hline & $\begin{array}{l}\text { Uncertainty about the future } \\
\text { (ther apies, prognosis) }\end{array}$ & $\begin{array}{l}\text { "Thinking that I'm not going to be around for ny kids when they get married. Not } \\
\text { having a clear paih of what to do. Where is this going?" } \\
\text { "I don' want to be treated by a guessing game." }\end{array}$ \\
\hline & Antigen detection & $\begin{array}{l}\text { "But' we don 't know what it came from, and that's what the frustrating thing is too. I } \\
\text { had my apartment checked for fingus. It's all negative." }\end{array}$ \\
\hline & $\begin{array}{l}\text { Patient self-ed.cation through } \\
\text { internet resources" }\end{array}$ & $\begin{array}{l}\text { "I go into my phone and I Google everything and it gives a lot of information, but } \\
\text { the information they give it's not the same thing as yout there, talking to a doctor." }\end{array}$ \\
\hline \multirow{4}{*}{ Hypervigilance } & $\begin{array}{l}\text { Avoidance of actual or perceived } \\
\text { antigen }\end{array}$ & $\begin{array}{l}\text { "So I know to stav away from any kind of dist, and we are going out tomorrow" } \\
\text { night with a friend and she ahways wears perfiune. I said," "please cion't wear your } \\
\text { perfiume" because I don't know what sets it off." }\end{array}$ \\
\hline & Increased awareness & $\begin{array}{l}\text { "It's always there, So in a bad situation with mold or something that I don't know } \\
\text { about, I'in concerned that I could start getting the symptoms again." }\end{array}$ \\
\hline & $\begin{array}{l}\text { Rumination about potential } \\
\text { exposures }\end{array}$ & $\begin{array}{l}\text { "I was scratching my head as to why, what aid I breathe in? What am I sensitive to } \\
\text { and can! do the best that I can to stay away from that?" }\end{array}$ \\
\hline & Focusing on objective cata & $\begin{array}{l}\text { "I hate that little oximeter because I'll be sitting here and I'il feel fine, but the } \\
\text { oximeter says you're } 90 \text { " }\end{array}$ \\
\hline \multirow{4}{*}{ Psychosocial } & Mental and emotional well-being & "Ifeel, emotionally, very bad" \\
\hline & Lmployment/Tinances & $\begin{array}{l}\text { "When you are doing rule out everything, you have to do the mold tiesting, and that } \\
\text { was an expensive thing to do." }\end{array}$ \\
\hline & $\begin{array}{l}\text { Impact on home or employment } \\
\text { due to remediation and antigen } \\
\text { avoidance }\end{array}$ & $\begin{array}{l}\text { "I literally didn't go back home for severai months because I just didn't feel good } \\
\text { when I went back in. Then psychologically. I had trouble staving there and we } \\
\text { decided io downsice so we sold it." }\end{array}$ \\
\hline & Lifestyle changes & "So life has changed a lot. I was always going out" \\
\hline \multirow{4}{*}{ Physical impacts } & Pulmonary symptoms & $\begin{array}{l}\text { "Well, if I go to a lumcheon or a party, I can't dance, I take a slow dance for a } \\
\text { couple of minutes, and that's it. I get out of breath." }\end{array}$ \\
\hline & Energy leve/Fatigue & $\begin{array}{l}\text { "I don't get out of breath when I walk I feel like I have to stop because I'm } \\
\text { farigued. In fantigued inost of the thue, and I feel like I wamt to sleep and sleep and } \\
\text { sleep." }\end{array}$ \\
\hline & Activity limitations & $\begin{array}{l}\text { "It was the inahility to do the things, the activities that I had done in the past, } \\
\text { especially with my grandchildren. Thet was difficult. And because they expected it. } \\
\text { And it was difficuit to have to be the one that ahways had to rest when everyone else } \\
\text { was enjoying themselves" }\end{array}$ \\
\hline & Supplemental Oxygea & $\begin{array}{l}\text { "It becomes kind of heary and it's sort of a chore in itself, carying the axygen } \\
\text { around." }\end{array}$ \\
\hline \multirow{4}{*}{ Interpersonal } & $\begin{array}{l}\text { Effects on family members and } \\
\text { relationships }\end{array}$ & "It put a lot of stress on my wife" \\
\hline & Social participation & $\begin{array}{l}\text { "I'll go to my exercise and that really seems to drain me so that by the time- then if } \\
\text { I want to go to uny knitting group, I'n exhausted because that person has statrcases } \\
\text { to get into their house" }\end{array}$ \\
\hline & Support systems & $\begin{array}{l}\text { "She's been there eveny step of the way and veny, very supportive. And that's made a } \\
\text { big difference" }\end{array}$ \\
\hline & $\begin{array}{l}\text { Other peoples' perceptions of } \\
\text { CHP }\end{array}$ & $\begin{array}{l}\text { "Ijust feel shame, a linle bit, of going ourside, to a place where I might start } \\
\text { coughing, and the people look at me like I have a kind of disease that can be } \\
\text { contagious." }\end{array}$ \\
\hline \multirow{4}{*}{$\begin{array}{l}\text { Self-perception } \\
\text { and identity }\end{array}$} & Indeperdenee & "Well, it conid be worse, At least I'm independen" \\
\hline & View of one's own health & $\begin{array}{l}\text { "I've always hod a problem addressing how sick I am. In iny heod, I doar't think I } \\
\text { ant as sick as I am" }\end{array}$ \\
\hline & $\begin{array}{l}\text { Impact of symptoms and } \\
\text { therapies }\end{array}$ & $\begin{array}{l}\text { "Prednisone has given me the noon face. Ilook different than what I looked before. } \\
\text { I gained weight, and I find it difficult to accept." }\end{array}$ \\
\hline & $\begin{array}{l}\text { Perecived threat and severity of } \\
\text { disease }\end{array}$ & "To live with this for the rest of my life. That is my worry" \\
\hline
\end{tabular}

Figure 1 Thematic framework for living with CHP. CHP, chronic hypersensitivity pneumonitis.

"When I first got the diagnosis, it was a sucker punch, it was very depressing."

"And it's really painful, really. If the mold has been detected, earlier, I wouldn't have been breathing all that mold. Sometimes I cry. What can I do?

Patients described effects on their home life related to relocation and monetary cost of home inspection and remediation.

"It was terrible, real. Even now, I'm not adjusted to the dislocation, or relocation. I'm dying to go back to my own home.

It was not uncommon that the disease affected a person's finances or employment status. This was manifested as either the ability to perform one's job, decision for early retirement or the loss of employment completely. There were financial effects related to loss of employment, medical bills and home mould inspections and remediation.

$$
\text { "I am under permanent disability. }
$$

Theme 4: the physical impacts of CHP go beyond just symptoms

Not surprisingly, dyspnoea and cough were common symptom complaints among patients with CHP. Patients described a cough that is sudden, extreme, unremitting and sometimes associated with embarrassment. 
Every time I try to do something I have to start coughing, and that's made my life miserable."

Dyspnoea was often associated with activity and for some led to a feeling of panic and fear of engaging in physical activity. Others made substantial efforts to adjust their daily activities in order to avoid feeling breathless. Many patients limited social interactions and recreational activities that require them to be physically active.

"Well it's almost better to be dead, because I can't go outside.

Many patients experienced fatigue, described as an overwhelming lack of energy and loss of stamina very distinct from breathlessness. Some patients reflected on the amount of extraeffort they need to put forth in order to complete the same activities as in the past. Sometimes fatigue was accompanied by feelings of guilt for needing to rest.

"It's like walking through thick mud just to get through everything. You have to just try harder. It's a struggle to do everyday kinds of things and just to go run errands, to go grocery shopping, being motivated to sit at the desk and do desk work.

Patients describe mixed emotions about supplemental oxygen. While seen as beneficial for increasing stamina and improving functioning, others felt it was a major life altering hindrance to their everyday activities.

"I mean the ad shows this little concentrator that weighs four pounds, a woman with a tennis racket. I mean, really, you can't play tennis with it. I mean it's just you know they want to make you think it's normal, but it's not.

Despite the impacts of CHP on patients' physical functioning and activity many patients conveyed a strong motivation to remain active from both the standpoint of improved lifestyle and therapy.

\section{Theme 5: living with CHP impacts relationships and daily interpersonal interactions}

Patients described the profound impact of CHP on family members and relationships. It was not uncommon that family members took on more responsibility in the household sometimes precipitating stress and feelings of guilt.

"I feel very guilty because the choices I make impact my family. If I choose to do something that's really important to me and it makes me feel very tired, I need a day or two to recover and that impacts them, then they have to do a little bit more.

Patients found themselves unable to interact with family members due to physical restrictions and to some extent due to their level of vigilance to avoid an antigen or a superimposed illness. Many patients described an inability to travel and visit family due to concerns with becoming ill among crowds and due to difficulties navigating travel with supplemental oxygen. These barriers kept them from seeing loved ones for longer periods at a time.

"But if I go there, then I have to think about taking oxygen on the plane, in their house"

Most patients described a solid support system comprised mostly of family members but also of those in their community.

"I have a very supportive partner. If everybody could have the support I have people would be in really good shape

Despite the support that was described, some patients feel that there is a lack of understanding of the disease by others, which at times leads to a lack of empathy.

"So the awkward part was explaining to people who have absolutely no idea about this and absolutely no compassion"

\section{Theme 6: CHP impacts patients' self-perception and identity}

Patients frequently commented on their own perception of their health, and how the disease impacts their identity. Patients described a change from the once healthy person they saw themselves as to adjusting to life with CHP. The negative consequences of therapies for CHP such as prednisone and supplemental oxygen were often mentioned.

"It was almost like the treatment was as bad or worse than the actual disease."

"The oxygen keeps me from going places, like to my local market. If I need to use it, I'll go to a market where no one knows me.

Participants spoke of the value they place on their independence. They expressed a concern for losing the ability to care for themselves and their loved ones.

"Now I can take care of myself, but if I reach a state that I cannot take care of myself, I dread that."

Many participants relayed the desire to remain 'normal' despite their illness. Despite difficulties experienced from the disease, many view themselves as healthy. Participants describe a great deal of resilience.

"I try not to let this interfere with who I am and what I do. I'm not going to let this disease define me"

\section{DISCUSSION}

This qualitative study revealed the perspectives of patients living with CHP in regard to the disease-related factors that influence their quality of life. We identified several key themes including the impact of knowledge deficits, which in some cases may cause profound suffering; hypervigilance and the intrusiveness of the need to plan around a potential exposure; the impact of symptoms, with a strong emphasis on fatigue rather than shortness of breath as might have been anticipated; the impact on interpersonal relationships and perceptions of self and 
psychosocial consequences. To our knowledge, this is the first report of the patient with CHP perspective on how CHP impacts their quality of life, and the findings reveal that there are several important and potentially targetable dimensions.

The theme 'Suffering due to knowledge and uncertainty' highlights profound and often underemphasised effects of knowledge deficits. While diagnostic uncertainty is common in ILD, for patients with CHP, this is compounded by the need to identify an antigen, lack of formal diagnostic criteria and limited data on efficacy of current therapies. While we do have some new clinical trial information on use of antifibrotics in progressive fibrotic CHP, we have little other data regarding the other therapies that are used..$^{341718}$ The suffering associated with this lack of knowledge can be contrasted to other ILDs such as CTD-ILD (Connective Tissue Disease- Interstitial Lung Disease) and IPF where there is more information available about diagnosis, prognosis and treatments that are prescribed. ${ }^{19-24}$ Even the patients in this study, who had all previously received a definitive diagnosis of CHP, still experienced confusion, frustration and fear about treatment options, prognosis and the future. The 'Physical impacts of CHP' theme highlights the often debilitating symptom of fatigue, separate from breathlessness, with the potential to cause profound disruption to everyday life. While this is the first time fatigue has been qualitatively described in detail by patients with CHP, this symptom has been endorsed in qualitative studies of patients with IPF. ${ }^{11}$ Whether the fatigue described by patients in this study is related solely to the underlying CHP or a combination of factors including medication use and comorbidities (several of our patients had obstructive sleep apnoea and hypothyroidism) is not known. Our qualitative findings about fatigue are consistent with findings of Lubin et al; fatigue was endorsed in $87 \%$ of patients with CHP in their sample. This was a higher prevalence than in the patients with IPF, which may point to one factor that worsens HRQOL in patients with CHP compared with patients with IPF. $^{8}$ Fatigue is an understudied symptom that warrants further investigation into prevalence and aetiologies as well as targeted therapies for patients with CHP. The 'psychosocial' theme highlights several key factors influencing CHP patients' quality of life such as the inability to work due to disability of illness, antigen avoidance or financial constraints imposed by home remediation, medical bills or oxygen. While there are undoubtedly psychosocial impacts associated with all ILDs, the need to identify and avoid an antigen adds a unique level of complexity to the impact of HRQOL in CHP. It is striking to learn how the search for and/ or avoidance of an antigen can impact the comfort of one's home environment, whether it be from the need to renovate, or move. There is currently no recommended approach for supporting patients to handle the complex issues related to antigen identification, avoidance and remediation, and unfortunately the psychosocial impact may be substantial. The 'self-perception and identity' theme highlights the effects that CHP therapies have on physical and mental health. While initially for some patients the positive impact of prednisone on physical functioning and symptom improvement is profound, we learnt that these benefits are mitigated to some extent by side effects that impact identity, self-perception and well-being.

The findings in this study support our clinical impressions regarding the effects that antigen identification and avoidance have on CHP patients' lives. The 'hypervigilance' theme was composed of mostlysubthemes that capture patients' thoughts and actions to avoid an inciting antigen. Interestingly, this effect was prevalent among patients with both known and unknown antigen exposures. This is a unique factor that impacts several domains of quality of life in patients with CHP and distinguishes it from other ILDs such as IPF. ${ }^{9}$ We found that the need to identify and avoid an antigen plays a role in quality of life through all phases of the disease trajectory. The need to identify an antigen affects patients at time of diagnosis, and unfortunately antigen identification and avoidance remains an ongoing factor throughout treatment and beyond.

The role that antigen identification and avoidance has on quality of life is not routinely explored in the clinical evaluation of patients with CHP, nor in the instruments we use to measure HRQOL in ILD. In fact, to our knowledge, there is no HRQOL instrument whether generic or ILD disease specific that comprehensively measures the themes and subthemes of CHP-HRQOL (including fatigue, self-perception and identity, medication side effects, effects of oxygen use, effects of antigen identification and avoidance) that were identified in this qualitative study. ${ }^{25-28}$

Overall the findings in this study suggest that there are key factors influencing quality of life in patients with CHP that have not been adequately explored. These warrant consideration for inclusion in HRQOL assessment and development of targeted interventions to improve overall quality of life in this patient population. We have hope that in the future, additional therapies with more tolerable side effects will be explored. ${ }^{29}$ As this research unfolds, assessing the effect of new treatment options on overall quality of life will be important, as will understanding and managing the impacts of the side effects of these medications. We also have an opportunity to shift our care plans for patients with CHP by devising innovative and multidisciplinary treatment approaches that include interventions to address many of these complex quality of life issues. This will include developing easier and more affordable approaches to antigen identification and avoidance with better sensitivity and specificity, development of support and education programmes, inclusion of multidisciplinary stakeholders in the design of care implementation, and importantly, the inclusion of patient input into the designs of these care management interventions. We must ensure we do not leave patients alone, desperately searching the internet for information 
that is often not accurate and may be harmful. ${ }^{30}$ Additionally, as we formulate methods to better identify causative antigens in CHP, we should consider that the psychosocial impact may not completely subside once we believe an antigen is successfully identified and symptoms are improved.

The strengths of our study include the unique findings, and the use of rigorous qualitative research methods (checklist of core qualitative research criteria available in online supplementary 2) ${ }^{31}$ Some limitations should be born in mind. The sample size is small, however, this is common with qualitative research, and we reached saturation of themes, continued with additional interviews and used respondent validation. Additionally, patients were recruited from a single academic urban quaternary referral centre, which may limit generalisability. Despite this, participants did travel from a wide geographical area that encompassed suburban communities and rural farm communities. Lastly, we excluded non-English speakers which may limit our understanding of experiences living with the illness that differs across cultures.

\section{CONCLUSIONS}

CHP impacts patients' lives in major ways in addition to symptoms, including suffering that stems from knowledge deficits, the need to identify and avoid an antigen, impacts on identity and relationships, and psychosocial issues. Patients placed a great deal of emphasis on the impact of fatigue, similar to other symptoms of CHP that may receive greater clinical attention. Antigen identification and avoidance is a key factor that influences several of the identified themes in this CHP framework, and is a large factor in the diagnosis and management of patients with CHP. These findings suggest that patients with CHP require a broader, multidisciplinary treatment approach if physicians are to optimise quality of life in these patients. Using the results of this study, we developed a novel disease-specific patient-centred framework for both future studies of quality of life, as well as the clinical management of CHP.

Contributors Conception and design: KIA, BJH, LR, RJK, FJM and MMS. Data collection: KIA and BJH. Data Analysis and interpretation: KIA, BJH, LR and MMS Drafting of the manuscript: KIA. Revising the manuscript critically for important intellectual content: KIA, BJH, LR, RJK, FJM and MMS. Final approval of the version to be published: KIA, BJH, LR, RJK, FJM and MMS.

Funding The authors have not declared a specific grant for this research from any funding agency in the public, commercial or not-for-profit sectors.

Competing interests None declared.

Patient consent for publication Not required.

Ethics approval The Weill Cornell Medical College Institutional Review Board approved the study protocol.

Provenance and peer review Not commissioned; externally peer reviewed.

Data availability statement Data are available upon reasonable request.

Open access This is an open access article distributed in accordance with the Creative Commons Attribution Non Commercial (CC BY-NC 4.0) license, which permits others to distribute, remix, adapt, build upon this work non-commercially, and license their derivative works on different terms, provided the original work is properly cited, appropriate credit is given, any changes made indicated, and the use is non-commercial. See: http://creativecommons.org/licenses/by-nc/4.0/.

\section{REFERENCES}

1 Lederer DJ, Martinez FJ. Idiopathic pulmonary fibrosis. N Engl J Med Overseas Ed 2018;378:1811-23.

2 Fernández Pérez ER, Kong AM, Raimundo K, et al. Epidemiology of hypersensitivity pneumonitis among an insured population in the United States: a Claims-based cohort analysis. Ann Am Thorac Soc 2018:15:460-9.

3 Morisset J, Johannson KA, Vittinghoff E, et al. Use of mycophenolate mofetil or azathioprine for the management of chronic hypersensitivity pneumonitis. Chest 2017;151:619-25.

4 Adegunsoye A, Oldham JM, Fernández Pérez ER, et al. Outcomes of immunosuppressive therapy in chronic hypersensitivity pneumonitis. ERJ Open Research 2017;3:1-11.

5 Fernández Pérez ER, Swigris JJ, Forssén AV, et al. Identifying an inciting antigen is associated with improved survival in patients with chronic hypersensitivity pneumonitis. Chest 2013;144:1644-51.

6 Mooney JJ, Elicker BM, Urbania TH, et al. Radiographic fibrosis score predicts survival in hypersensitivity pneumonitis. Chest 2013;144:586-92.

7 Salisbury ML, Myers JL, Belloli EA, et al. Diagnosis and treatment of fibrotic hypersensitivity pneumonia. where we stand and where we need to go. Am J Respir Crit Care Med 2017;196:690-9.

8 Lubin $\mathrm{M}$, Chen $\mathrm{H}$, Elicker $\mathrm{B}$, et al. A comparison of healthrelated quality of life in idiopathic pulmonary fibrosis and chronic hypersensitivity pneumonitis. Chest 2014;145:1333-8.

9 Barber CM, Wiggans RE, Fishwick D. Impaired quality of life in chronic hypersensitivity pneumonitis. Chest 2015;147:e230.

10 Swigris JJ, Stewart AL, Gould MK, et al. Patients' perspectives on how idiopathic pulmonary fibrosis affects the quality of their lives. Health Qual Life Outcomes 2005;3:61.

11 Schoenheit G, Becattelli I, Cohen AH. Living with idiopathic pulmonary fibrosis: an in-depth qualitative survey of European patients. Chron Respir Dis 2011;8:225-31.

12 Strauss A, Corbin J. Basics of Qualitative Resaerch: Second Edition: Techniques and Procedures for Developing Grounded Theory. 2nd edn. SAGE Publications, 1998.

13 Boeije H. A purposeful approach to the constant comparative method in the analysis of qualitative interviews. Quality and Quantity 2002;36:391-409.

14 Guest G, Bunce A, Johnson L. How many interviews are enough?: an experiment with data saturation and variability. Field methods 2006;18:59-82

15 Fusch P, Ness L. Are we there yet? data saturation in qualitative research. The Qualitative Report 2015;20:1408-16.

16 Triangulation $\mathrm{TH}$. Respondent validation, and Democratic participation in mixed methods research. J Mix Methods Res 2012;6:111-23.

17 Flaherty KR, Wells AU, Cottin V, et al. Nintedanib in progressive fibrosing interstitial lung diseases. N Engl J Med 2019;381:1718-27.

18 Kokkarinen JI, Tukiainen HO, Terho EO. Effect of corticosteroid treatment on the recovery of pulmonary function in farmer's lung. Am Rev Respir Dis 1992;145:3-5.

19 Tashkin DP, Roth MD, Clements PJ, et al. Mycophenolate mofetil versus oral cyclophosphamide in scleroderma-related interstitial lung disease (SLS II): a randomised controlled, double-blind, parallel group trial. Lancet Respir Med 2016;4:708-19.

20 Volkmann ER, Tashkin DP, Li N, et al. Mycophenolate mofetil versus placebo for systemic sclerosis-related interstitial lung disease: an analysis of scleroderma lung studies I and II. Arthritis Rheumatol 2017;69:1451-60.

21 Raghu G, Anstrom KJ, King TE, et al. Prednisone, azathioprine, and $\mathrm{N}$-acetylcysteine for pulmonary fibrosis. $N$ Engl $\mathrm{J}$ Med 2012;366:1968-77.

22 Richeldi L, du Bois RM, Raghu G, et al. Efficacy and safety of nintedanib in idiopathic pulmonary fibrosis. $N$ Engl J Med 2014;370:2071-82.

23 Raghu G, Remy-Jardin M, Myers JL, et al. Diagnosis of idiopathic pulmonary fibrosis. An official ATS/ERS/JRS/ALAT clinical practice guideline. Am J Respir Crit Care Med 2018;198:e44-68.

24 King TE, Bradford WZ, Castro-Bernardini S, et al. A phase 3 trial of pirfenidone in patients with idiopathic pulmonary fibrosis. $N$ Engl J Med 2014;370:2083-92.

25 Jones PW, Quirk FH, Baveystock CM. The St George's respiratory questionnaire. Respir Med 1991;85:25-31.

26 Rabin R, Charro Fde, de CF. EQ-SD: a measure of health status from the EuroQol group. Ann Med 2001;33:337-43. 
27 Brazier JE, Harper R, Jones NM, et al. Validating the SF-36 health survey questionnaire: new outcome measure for primary care. $B M J$ 1992;305:160-4.

28 Patel AS, Siegert RJ, Brignall K, et al. The development and validation of the King's brief interstitial lung disease (K-BILD) health status questionnaire. Thorax 2012;67:804-10.

29 Vasakova M, Selman M, Morell F, et al. Hypersensitivity pneumonitis: current concepts of pathogenesis and potential targets for treatment. Am J Respir Crit Care Med 2019;200:301-8.
30 Fisher JH, O'Connor D, Flexman AM, et al. Accuracy and reliability of Internet resources for information on idiopathic pulmonary fibrosis. Am J Respir Crit Care Med 2016;194:218-25.

31 Tong A, Sainsbury P, Craig J. Consolidated criteria for reporting qualitative research (COREQ): a 32-item checklist for interviews and focus groups. Int J Qual Health Care 2007;19:349-57. 